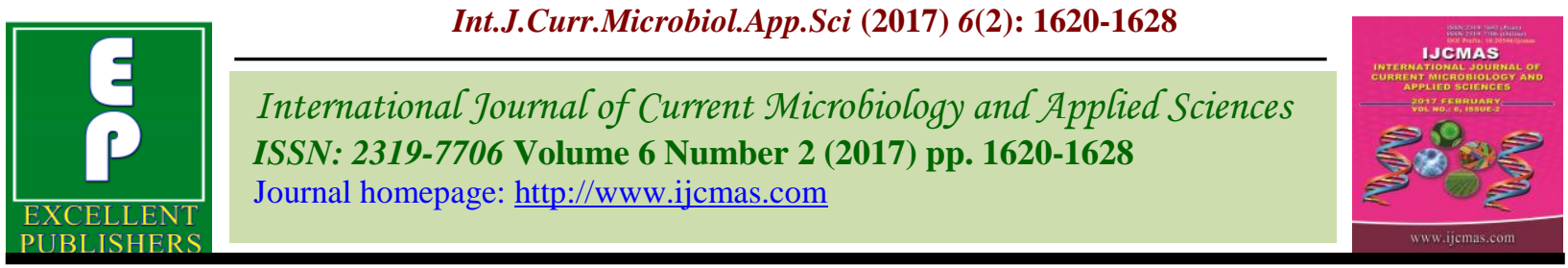

Original Research Article

http://dx.doi.org/10.20546/ijcmas.2017.602.180

\title{
Studies on Life Fecundity Tables of $L$. orbonalis Guenee on Brinjal
}

\author{
S. Ramesh* and C. Narendra Reddy \\ Department of Entomology, College of Agriculture, Rajendranagar, \\ PJTSAU, Hyderabad-500030, India \\ *Corresponding author
}

\section{A B S T R A C T}

Keywords

Leucinodes orbonalis,

Life table,

Brinjal.

\section{Article Info}

Accepted:

24 January 2017

Available Online:

10 February 2017
The life table of Leucinodes orbonalis was prepared from daily fecundity and survival of cohort, when larvae were reared on brinjal c.v. Shyamala at a temperature $26 \pm 1^{0} \mathrm{C}$. Results on the survival of different stages of L.. orbonalis indicated $10 \%$ mortality in the egg stage and with $20 \%$ and $28 \%$ mortality in the larval and pupal stages, respectively. The longest duration of egg incubation was 5 days, while the larval and pupal periods were 18 days and 11 days, respectively. The number that survived from egg to adult emergence was 72 individuals. The net reproductive rate (Ro) was 136.35 with mean length generation (Tc) 38.05 days. The intrinsic rate of increase was 0.1294 females female ${ }^{-1}$ day and population multiplied 2.4739 times in a week with generation time of 37.98 days on brinjal. The per cent contribution of eggs, larval, pupal and adults were 58.98, 37.65, 2.50 and 0.42 , respectively at stable age distribution of L.orbonalis on brinjal. Life expectancy of $L$. orbonalis on brinjal for newly deposited eggs was 13.24 days. The mortality rate was comparatively high at the age of 35 to 40 days when the expectation of further life was reduced to only 1.80 days from 13.24 days in the beginning.

\section{Introduction}

Brinjal (Solanum melongena) shoot and fruit borer Leucinodes orbonalis Guene is the most destructive pest causing major constraints in the production as well as in the quality of the crop. This pest reported to cause as high as 20-89 per cent crop loss to brinjal (Raju et al., 2007). The crop productivity of brinjal crop has been substantially reduced as a result of boring and feeding on the shoot and fruit Leucinodes orbonalis is the most noxious and obiquitus pest of brinjal Naik et al., (2009). Application of life table, rate of increase and stable age distribution are most as diverse as the insects. Such a life tables may be analyse to determine which stage, the life cycle of the insect contribute the most to the population trend. The study of life table of an insect provides the growth rate statistics which can be used as predictive basis of pest control. Since, brinjal cv Shyamala variety is grown as kharif crop in Telangana region and no detailed information regarding life tables at constant laboratory temperature is available, the present study are therefore, carried out.

\section{Materials and Methods}

The studies on the life-fecundity table of brinjal shoot and fruit borer was conducted under laboratory conditions at constant temperature of $26 \pm 1^{\circ} \mathrm{c}$ on brinjal fruits in Department of Entomology, College of 
Agriculture, Rajendranagar, Hyderabad. To construct the life table, 10 pairs of adults were kept for egg lay in wooden cages. The sides of the cages were covered with muslin cloth. Tender leaves of brinjal were inserted in to a conical flask containing fresh water to keep leaves fresh and turgid. The brinjal leaves along with conical flask and fresh brinjal fruits were placed in to the cage for resting and oviposition of adults. Eggs laid on muslin cloth or on leaves or on fruits were used for this study. In order to construct the life-tables, 100 eggs were collected carefully with the help of wet camel hair brush and placed in ten plastic containers in a batch of 10 each. The eggs were glued on black card paper in one row to facilitate observations on hatching. Immediately after hatching the larvae were transferred individually on brinjal fruit and Fresh food was provided daily. An observation on hatching, larval development, formation of pupae, successful emergence of adults and fecundity were recorded daily. To determine, age-specific fecundity, total number of adults emerged on the same day was caged for oviposition. Number of eggs laid on subsequent days on the brinjal fruit and muslin cloth was recorded until death of the adults. The life-fecundity tables under laboratory conditions were constructed by using the column headings proposed by Birch (1948), elaborated by Howe (1953), Southwood (1978) and Atwal and Bains (1974).

Details of the column heads used for the construction of life tables of pests are

$\mathrm{X}$ : Age of the insect in days,

$1_{\mathrm{x}}$ : Number surviving at the beginning of each interval, out of 100.

$\mathrm{d}_{\mathrm{x}}$ : Number dying during the age interval, out of 100 .

$100 \mathrm{qx}$ : Mortality rate at the age interval $\mathrm{x}$ and calculated by using formula.

$$
\begin{array}{lll}
100 \mathrm{qx} & : & \frac{\mathrm{dx}}{\mathrm{lx}} \times 100 \\
\mathrm{e}_{\mathrm{x}} & : & \text { Expectation of life or mean life remaining for individuals of age } \mathrm{x} . \\
\mathrm{e}_{\mathrm{x}} & : & \frac{\mathrm{Tx}}{\mathrm{lx}}
\end{array}
$$

To obtain life expectation $\left(e_{x}\right)$ two other parameters $L_{x}$ and $T_{x}$ were also computed as below.

$\mathrm{L}_{\mathrm{x}} \quad: \quad$ The number of individuals alive between ages.

$\mathrm{x}$ and $\mathrm{x}+1$ and calculated by the equation.

$\mathrm{L}_{\mathrm{x}} \quad: \quad 1_{\mathrm{x}}+\frac{(\mathrm{lx}+1)}{2}$

$\mathrm{T}_{\mathrm{x}} \quad$ : The total number of individual of $\mathrm{x}$ age units and beyond the age $\mathrm{x}$, and obtained by the equation.

$\mathrm{T}_{\mathrm{x}} \quad: \quad \mathrm{l}_{\mathrm{x}}+\left(\mathrm{l}_{\mathrm{x}}+1\right)+\left(\mathrm{l}_{\mathrm{x}}+2\right) \ldots \ldots \ldots \ldots \ldots+\mathrm{1}_{\mathrm{w}}$.

Where, $\quad 1_{\mathrm{w}} \quad: \quad$ The last age interval.

Life -Table (For Female) and Age-Specific Fecundity Table The table was constructed on the suggestions made by Birch (1948) and Southwood (1978). It consisted of following columns: 
$\mathrm{x} \quad$ : $\quad$ Pivotal age of female in days.

$1_{\mathrm{x}} \quad: \quad$ Number of females alive at the beginning of the age interval $\mathrm{x}$ (as fraction of initial population of one).

$\mathrm{m}_{\mathrm{x}} \quad$ : $\quad$ Average number of female eggs laid per female in each age interval assuming 50:50 sex ratio and computed as:

$\mathrm{m}_{\mathrm{x}} \quad: \quad \frac{\mathrm{Nx}}{2}$

Where, $\mathrm{N}_{\mathrm{x}}$ : Total natality per female off springs in each age.

$1_{\mathrm{x}} \mathrm{m}_{\mathrm{x}} \quad$ : $\quad$ Total number of births in each age interval.

This can multiply with column $1 \mathrm{x}$ and $\mathrm{m}_{\mathrm{x}}$ together.

Besides $\mathrm{m}_{\mathrm{x}}$ total number of female off springs in each age interval $(\mathrm{x}), \mathrm{l}_{\mathrm{x}}, \mathrm{m}_{\mathrm{x}}$ was also computed by multiplying the column $1_{\mathrm{X}}$ with $\mathrm{m}_{\mathrm{x}}$.

\section{Population Growth Attributes}

Net reproductive rate $\left(R_{0}\right)$ is the total number of female offspring's produced per female during single generation

Ro $\quad: \quad \sum 1_{\mathrm{x}} \mathrm{m}_{\mathrm{x}}$

Mean length of generation (or) approximate generation time, independent of ' $\mathrm{r}_{\mathrm{m}}$ ' or mean duration of generation

$\mathrm{T}_{\mathrm{c}} \quad: \quad \frac{\sum \mathrm{lnmx} x}{\mathrm{Ro}}$

Innate Capacity for increase

(r) $\quad: \quad \frac{\log _{\mathrm{e}} \mathrm{R}_{\mathrm{o}}}{\mathrm{T}}$

Where, e : natural $\log$ (i.e. 2.71828)

The above $r_{c}$ was an approximate value of intrinsic rate of natural increase $\left(\mathrm{r}_{\mathrm{m}}\right)$ and is slightly lower than $r_{m}$ value for insects with overlapping generations as suggested by Laughlin (1965) and Southwood (1978).

IV. ' $r_{\mathrm{m}}$ ' values (intrinsic rate of increase)
This approximate value $\left(\mathrm{r}_{\mathrm{c}}\right)$ and other provisional values $\left(\mathrm{r}_{\mathrm{m}}\right)$ were substituted in the following equation to obtain accurate value of intrinsic rate of increase (' $r_{m}$ ') as suggested by Atwal and Bains, 1974.

$\sum \mathrm{e}^{-\mathrm{rm} \cdot \mathrm{x}} 1 \mathrm{x} \mathrm{mx}=1$

Where, e : natural $\log (2.71828)$

Two trial values of ' $r_{m}$ ' differing two points in second decimal place were substituted in the above equation. In each case $e^{-r m}$ values multiplied with $1 x \mathrm{mx}$ values. These two trial values are selected such that until two values were found by trial and error, which lie immediately above and below ' 1 '. The trial ' $r$ ' values on $\mathrm{Y}$-axis and the summation value from the equation $\sum \mathrm{e}^{-\mathrm{rm} \cdot \mathrm{x}} \mathrm{lx} \mathrm{mx}$ on $\mathrm{X}$-axis were plotted on graph. The point of trial ' $r_{m}$ ' values against summation was connected by a straight line. The point on straight line at which it was intercepted with the vertical line drawn from established value, ' 1 ' from $\mathrm{X}$ axis, considered as ' $r_{m}$ ' value. This value is substituted in the above equation to check whether the summation is ' 1 ' or not. If it is not less than one then tried for another $r_{m}$ value, then the same procedure was repeated, until ' 1 ' was obtained. Finally, this value was considered as accurate ' $r_{m}$ ' value. From the ' $r_{m}$ ' value, the corrected generation time $(T)$, finite rate of increase $(\lambda)$ and weekly multiplication rate (WMR) were derived with the following formulae. 
Corrected generation time (T) : $\frac{\log _{\mathrm{e}} \mathrm{R}_{\mathrm{o}}}{\mathrm{r}_{\mathrm{m}}}$

Finite rate of increase $(\lambda): \quad$ anti $\log _{e} r_{m}$

Weekly multiplication rate (WMR): $\left(\mathrm{e}^{\mathrm{rm}}\right)^{7}$

Hypothetical $\mathrm{F}_{2}$ females $\quad: \quad\left(\mathrm{R}_{\mathrm{o}}\right)^{2}$

Doubling time $\quad: \quad \frac{\log _{\mathrm{e}}{ }^{2}}{\mathrm{r}_{\mathrm{m}}}$

Stable- age Distribution

The stable-age distribution of brinjal shoot and fruit borer was computed from the intrinsic rate of increase and life-tables, suggested by Birch (1948) and Atwal and Bains (1974).

From the number of individuals survived at age $(\mathrm{x})$ i.e. $\mathrm{lx}$ of life-table, the value of $\mathrm{Lx}$ was worked out by using the formula.

$$
\text { Lx } \quad \text { : } \quad 1 x+\frac{(1 x+1)}{2}
$$

The value, Lx was multiplied with $\mathrm{e}^{-\mathrm{rm}(\mathrm{x}+1)}$ to get the column of $\mathrm{Lx} \mathrm{e}^{-\mathrm{rm}(\mathrm{x}+1)}$. Then the birth rate $(\beta)$ was obtained from dividing one by $\sum$ Lx e $\mathrm{e}^{-\mathrm{rm}(\mathrm{x}+1)}$ value. The stable-age distribution was obtained by multiplying $\operatorname{Lx} \mathrm{e}^{-\mathrm{rm}(\mathrm{x}+1)}$ with $\beta$ and converted into percentage.

\section{Results and Discussion}

Results on the survival of different stages of L. orbonalis (Table 1) indicated $10 \%$ mortality in the egg stage and with $20 \%$ and $32 \%$ mortality in the larval and pupal stages, respectively. The longest maximum duration of eggs incubation was 5 days. The larval and pupal periods were 18, 11 days, respectively. Similar results were reported by Singh and Singh (2009) where the data on survival of different stages of $L$. orbonalis on brinjal revealed that the incubation period of egg was 4 days and larva, pupal duration was 19, 13 days, respectively. According to Pramanik and Chatterjee (2012) reported that larval period and pupal period, was 16.2, 7.6 days, respectively. The number that survived from egg to adult emergence was 72 individuals (Table 1). Life fecundity tables were constructed to determine the survival of female (lx) and age specific fecundity (mx). The life fecundity data indicated that pre oviposition period ranged from $34^{\text {th }}$ to $35^{\text {th }}$ day of pivotal age (Table 2). Females deposited first batch of eggs on $36^{\text {th }}$ day and stopped $40^{\text {th }}$ day with $1 x$ values 0.72 and 0.40 , respectively. The ' $\mathrm{x}$ 'values decreased gradually after $37^{\text {th }}$ day of the pivotal age due to adult mortality. The maximum fecundity (96.05) in the life cycle was made by on the $38^{\text {th }}$ day of pivotal age. The net reproductive $\left(R_{\mathrm{o}}\right)$ was worked out as 136.35 females female day $^{-1}$.These results are more or less confirmation with Jethva and Vyas (2009) reported the net reproductive rate $\left(R_{0}\right)$ was 160.96 females female day ${ }^{-1}$ on brinjal and Kumral et al., (2007) reported the net reproductive rate $\left(R_{0}\right)$ of olive leaf moth 129.8 females female ${ }^{-1}$ day $^{-1}$. The intrinsic rate of increase $\left(r_{m}\right) 0.1294$ females female day $^{-1}$ (figure 1) and population would be able to multiply 2.4739. Similar results reported by Jethva and Vyas (2009). Who reported that the intrinsic rate of natural increase in numbers $\left(r_{m}\right)$ was 0.1305 females female ${ }^{-1}$ day $^{-1}$ and the L. orbonalis population would be able to multiply 2.4931 times week $^{-1}$ on brinjal. 
Table.1 Survival of different developmental stages of shoot and fruit borer on brinjal

\begin{tabular}{|c|c|c|c|}
\hline \multirow{2}{*}{ No. of eggs } & \multicolumn{3}{|c|}{ Number survived } \\
\cline { 2 - 4 } & $\begin{array}{c}\text { Egg stage } \\
\mathbf{0 - 5} \text { days }\end{array}$ & $\begin{array}{c}\text { Larval stage } \\
\mathbf{6 - 2 3} \text { days }\end{array}$ & $\begin{array}{c}\text { Pupal stage } \\
\mathbf{2 4 - 3 4} \text { days }\end{array}$ \\
\hline \hline 10 & 8 & 7 & 6 \\
\hline 10 & 9 & 7 & 7 \\
\hline 10 & 9 & 8 & 7 \\
\hline 10 & 10 & 8 & 7 \\
\hline 10 & 9 & 9 & 7 \\
\hline 10 & 10 & 9 & 8 \\
\hline 10 & 9 & 8 & 6 \\
\hline 10 & 9 & 8 & 8 \\
\hline 10 & 9 & 8 & 8 \\
\hline 10 & 8 & 8 & $\mathbf{7 2}$ \\
\hline $\mathbf{1 0 0}$ & $\mathbf{9 0}$ & $\mathbf{8 0}$ & $\mathbf{2 8}$ \\
\hline Per cent mortality & $\mathbf{1 0}$ & $\mathbf{2 0}$ & 8 \\
\hline
\end{tabular}

Table.2 Life- table (for female) and age specific fecundity of shoot and fruit borer on brinjal

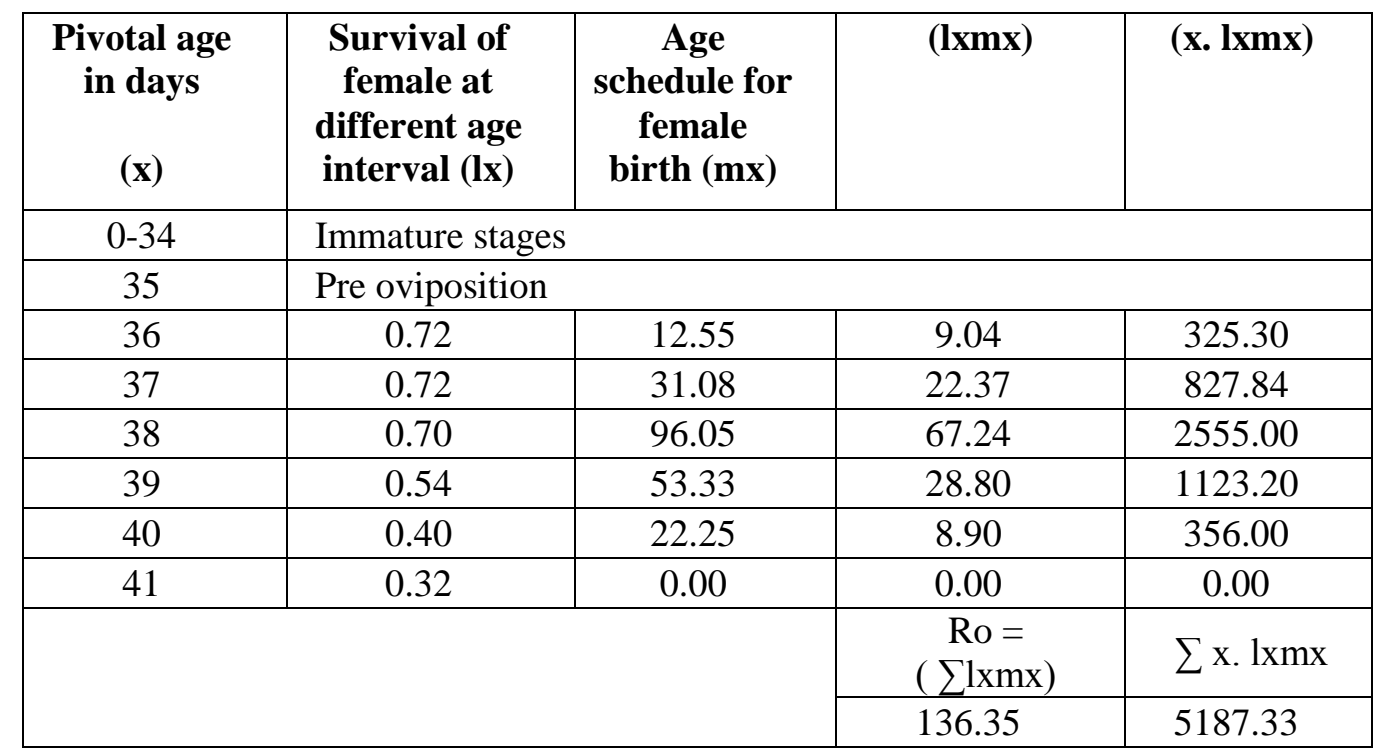


Table.3 Population growth attributes of shoot and fruit borer on brinjal

\begin{tabular}{|c|c|}
\hline Parameters & calculated value \\
\hline Net reproductive rate $\left(R_{\mathrm{o}}\right)$ & 136.35 \\
\hline Mean length of generation $\left(\mathrm{T}_{\mathrm{C}}\right)$ & 38.05 days \\
\hline Innate capacity for increase in number $\left(r_{c}\right)$ & 0.1292 females female $^{-1}$ day $^{-1}$ \\
\hline Trial ' $r_{\mathrm{m}}$ & 0.12 and 0.13 \\
\hline Corrected $r_{\mathrm{m}}$ & 0.1294 \\
\hline Corrected generation time $(\mathrm{T})$ & 37.98 days \\
\hline Finite rate of increase number $(\boldsymbol{\lambda})$ & 1.1381 females female $^{-1}$ day $^{-1}$ \\
\hline Weekly multiplication rate (WMR) & 2.4739 \\
\hline
\end{tabular}

Fig.1 Determination of intrinsic rate of increase (rm) of shoot and fruit borer

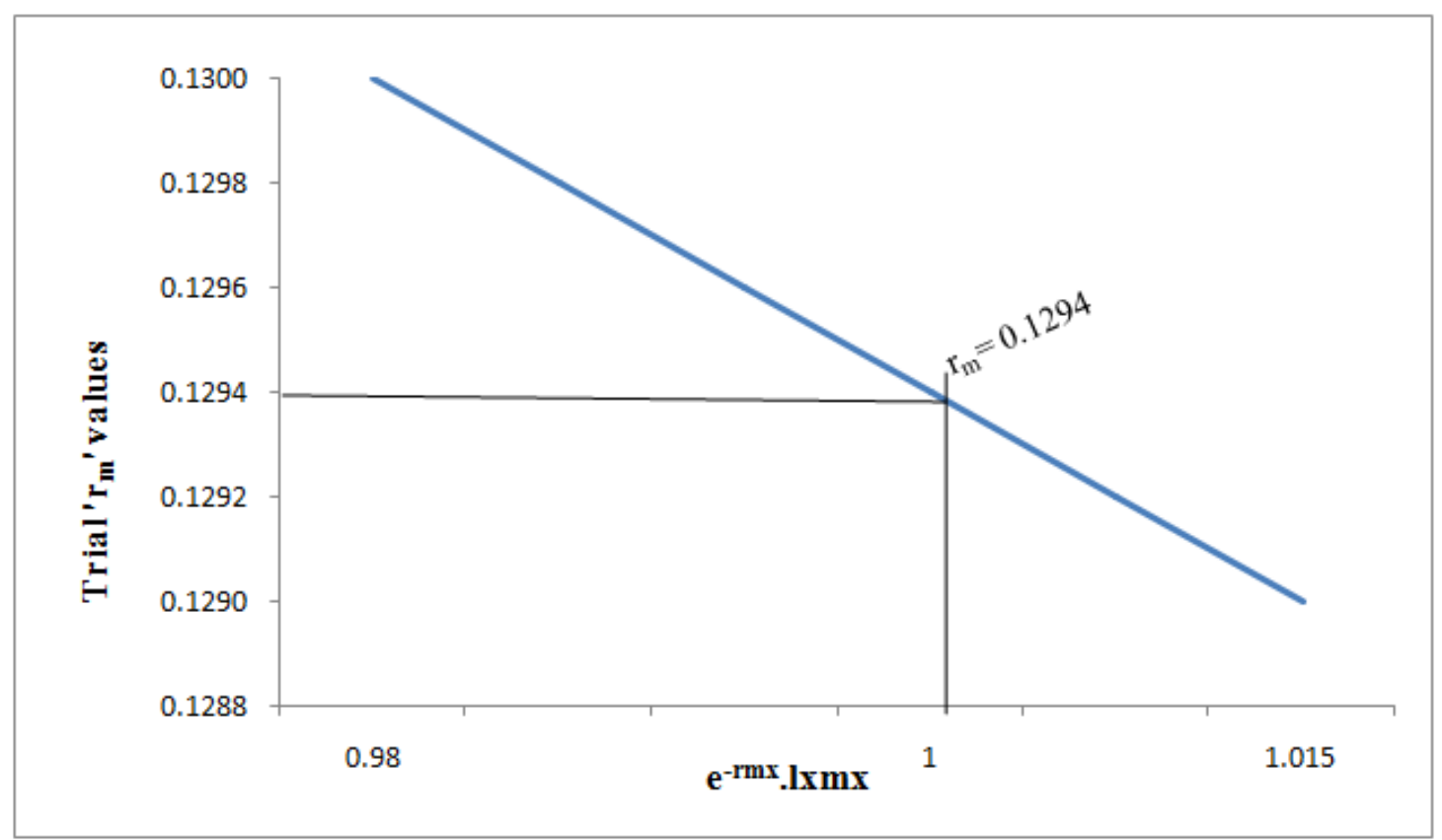


Table.4 Stable -age distribution of shoot and fruit borer on brinjal $(\mathrm{rm}=0.1294)$

\begin{tabular}{|c|c|c|c|c|}
\hline $\begin{array}{c}\text { Pivotal } \\
\text { age in (days) } x\end{array}$ & $\mathbf{L x}$ & $\mathrm{e}^{-\mathrm{rm}(\mathrm{x}+1)}$ & $\underset{\mathrm{e}^{-\mathrm{rm}(\mathrm{x}+1)}}{\mathbf{L x}}$ & $\begin{array}{c}\text { Percent } \\
\text { contribution }\end{array}$ \\
\hline 0 & 1.00 & 0.8786 & 0.8786 & 13.58 \\
\hline 1 & 1.00 & 0.7720 & 0.7720 & 11.93 \\
\hline 2 & 1.00 & 0.6783 & 0.6783 & 10.48 \\
\hline 3 & 0.99 & 0.5959 & 0.5900 & 9.12 \\
\hline 4 & 0.94 & 0.5236 & 0.4922 & 7.61 \\
\hline \multirow[t]{2}{*}{5} & 0.88 & 0.4601 & 0.4049 & 6.26 \\
\hline & & & & 58.98 \\
\hline 6 & 0.86 & 0.4042 & 0.3456 & 5.34 \\
\hline 7 & 0.83 & 0.3552 & 0.2930 & 4.53 \\
\hline 8 & 0.80 & 0.3120 & 0.2496 & 3.86 \\
\hline 9 & 0.80 & 0.2742 & 0.2193 & 3.39 \\
\hline 10 & 0.80 & 0.2409 & 0.1927 & 2.98 \\
\hline 11 & 0.80 & 0.2117 & 0.1693 & 2.62 \\
\hline 12 & 0.80 & 0.1860 & 0.1488 & 2.30 \\
\hline 13 & 0.80 & 0.1634 & 0.1307 & 2.02 \\
\hline 14 & 0.80 & 0.1436 & 0.1148 & 1.77 \\
\hline 15 & 0.80 & 0.1261 & 0.1009 & 1.56 \\
\hline 16 & 0.80 & 0.1108 & 0.0887 & 1.37 \\
\hline 17 & 0.80 & 0.0974 & 0.0779 & 1.20 \\
\hline 18 & 0.80 & 0.0856 & 0.0684 & 1.06 \\
\hline 19 & 0.80 & 0.0752 & 0.0601 & 0.93 \\
\hline 20 & 0.80 & 0.0660 & 0.0528 & 0.82 \\
\hline 21 & 0.80 & 0.0580 & 0.0464 & 0.72 \\
\hline 22 & 0.80 & 0.0510 & 0.0408 & 0.63 \\
\hline \multirow[t]{2}{*}{23} & 0.80 & 0.0448 & 0.0358 & 0.55 \\
\hline & & & & 37.65 \\
\hline 24 & 0.80 & 0.0394 & 0.0315 & 0.49 \\
\hline 25 & 0.80 & 0.0346 & 0.0277 & 0.43 \\
\hline 26 & 0.80 & 0.0304 & 0.0243 & 0.38 \\
\hline 27 & 0.80 & 0.0267 & 0.0214 & 0.33 \\
\hline 28 & 0.80 & 0.0235 & 0.0188 & 0.29 \\
\hline 29 & 0.80 & 0.0206 & 0.0165 & 0.25 \\
\hline 30 & 0.78 & 0.0181 & 0.0141 & 0.22 \\
\hline 31 & 0.74 & 0.0159 & 0.0118 & 0.18 \\
\hline 32 & 0.72 & 0.0140 & 0.0101 & 0.16 \\
\hline 33 & 0.72 & 0.0123 & 0.0088 & 0.14 \\
\hline \multirow[t]{2}{*}{34} & 0.72 & 0.0108 & 0.0078 & 0.12 \\
\hline & & & & 2.50 \\
\hline 35 & 0.72 & 0.0095 & 0.0068 & 0.11 \\
\hline 36 & 0.72 & 0.0083 & 0.0060 & 0.09 \\
\hline 37 & 0.71 & 0.0073 & 0.0052 & 0.08 \\
\hline 38 & 0.62 & 0.0064 & 0.0040 & 0.06 \\
\hline 39 & 0.47 & 0.0057 & 0.0027 & 0.04 \\
\hline 40 & 0.36 & 0.0050 & 0.0018 & 0.03 \\
\hline \multirow[t]{2}{*}{41} & 0.16 & 0.0044 & 0.0007 & 0.01 \\
\hline & & & & 0.42 \\
\hline
\end{tabular}


Table.5 Life-table for computing life expectancy of shoot and fruit borer reared on brinjal

\begin{tabular}{|c|c|c|c|c|c|c|}
\hline $\begin{array}{c}\text { Pivotal } \\
\text { age in } \\
\text { days } \\
\text { (x) }\end{array}$ & $\begin{array}{l}\text { Number surviving to } \\
\text { the begging of age } \\
\text { interval } \\
\text { (lx) }\end{array}$ & $\begin{array}{c}\begin{array}{c}\text { Numbers } \\
\text { dying } \\
\text { during } x\end{array} \\
\text { (dx) }\end{array}$ & $\begin{array}{c}\text { Mortality } \\
\text { rate per } \\
\text { hundred } \\
\text { alive at } \\
\text { begging of } \\
\text { age interval } \\
\frac{\mathbf{d x}}{\mathbf{l x}} \times 100 \\
\end{array}$ & 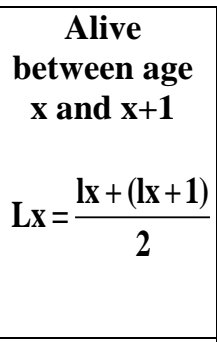 & $\begin{array}{c}\text { Numbers of } \\
\text { the } \\
\text { individual's } \\
\text { days beyond } x \\
\text { (Tx) }\end{array}$ & $\begin{array}{c}\begin{array}{c}\text { Expectin } \\
\text { g of } \\
\text { further } \\
\text { life }\end{array} \\
\mathrm{e}_{\mathrm{x}}=\frac{\mathrm{Tx}}{\mathrm{lx}} \times 2\end{array}$ \\
\hline $0-5$ & 100 & 10.00 & 10.00 & 95.00 & 662.00 & 13.24 \\
\hline $5-10$ & 90 & 10.00 & 11.11 & 85.00 & 567.00 & 12.60 \\
\hline $10-15$ & 80 & 0.00 & 0.00 & 80.00 & 482.00 & 12.05 \\
\hline $15-20$ & 80 & 0.00 & 0.00 & 80.00 & 402.00 & 10.05 \\
\hline $20-25$ & 80 & 0.00 & 0.00 & 80.00 & 322.00 & 8.05 \\
\hline $25-30$ & 80 & 6.00 & 7.50 & 77.00 & 242.00 & 6.05 \\
\hline $30-35$ & 74 & 2.00 & 2.70 & 73.00 & 165.00 & 4.46 \\
\hline $35-40$ & 72 & 32.00 & 44.44 & 56.00 & 92.00 & 2.56 \\
\hline $40-45$ & 40 & 8.00 & 20.00 & 36.00 & 36.00 & 1.80 \\
\hline
\end{tabular}

The difference in results might be due to nutritional quality of host plants and weather conditions which was provided as food to the pest during larval development (Gedia et al., 2007). The mean length time required for completing the life cycle to complete one generation was 37.98 days and finite rate of increase $(\boldsymbol{\lambda}) 1.1381$ females female $\mathrm{day}^{-1}$. The results are in conformity with those Jethva and Vyas (2009) reported mean length time of L. orbonalis 38.9 days and finite rate of increase $(\lambda)$ of 1.1394 females female $^{-1}$ day $^{-1}$ on brinjal. Gedia et al., (2008) who reported mean generation period of $S$. litura 39.75 days on cotton. Singh and Singh (2009) reported finite rate of increase $(\lambda) 1.14$ females female ${ }^{1}$ day $^{-1}$ of $L$. orbonalis on brinjal. The per cent contribution of various developmental stages for the stable-age distribution pattern (Table 3) was $58.98,37.65,2.5$ and 0.42 per cent in egg, larvae, pupae and adult stages. Similar results were also reported by Acharya et al., (2007) with their studies on Helicoverpa armigera on cotton. The data revealed that the stable age distribution pattern were 43.7, 51.1, 4.7 and 0.4 per cent contribution in egg, larvae, pupae and adult stages. Singh and Singh (2009) reported 58.3, 39.8, 1.7 and 0.3 per cent contribution in egg, larvae, pupae and adult stages on brinjal. The compution of life expectancy table of $L$. orbonalis on brinjal c.v. Shyamala (Table 4). Life expectancy of L. orbonalis on brinjal for newly deposited eggs was 13.24 days. The mortality rate was comparatively high at the age of 35 to 40 days when the expectation of further life was reduced to only 1.80 days from 13.24 days in the beginning. The present findings were in conformity with the observations made by Dabhi and Patel (2007) on H armigera, Singh and Singh (2009) and Jethva and Vyas (2009) on shoot and fruit borer on brinjal.

\section{References}

Acharya, M.F., Vyas, H.J., Gedia, M.V. and Patel, P.V. 2007. Life table, intrinsic rate of increase and age specific distribution of Helicoverpa armigera on cotton. Annals of Plant Protection Sci., 15: 338-341.

Atwal, A.S. and Bains, S.S. 1974. Appl. 
Animal Ecol., Kalyani Publications., Ludhiana, 128- 135.

Birch, L.C. 1948. The intrinsic rate of natural increase of an insect population. J. Ani. Ecol., 17: 15-26.

Dabhi, M.V. and Patel, C.C. 2007. Life expectancy of Helicoverpa armigera on chickpea. J. SAT Agri. Res., 5(1): 1-2.

Gedia, M.V., Vyas, H.J. and Acharya, M.F. 2007. Influence of weather parameters on Spodoptera litura in pheromone trap and oviposition on groundnut. Annals of Plant Protect. Sci., 15: 316-320.

Howe, R.W. 1953. The rapid determination of intrinsic rate of increase of an insect population. Annals of Appl. Biol., 40: 134-135.

Jethva, D.M. and Vyas, H.J. 2009. Studies on life fecundity table of Leucinodes orbonalis Guenee on brinjal. Annals of Plant Protection Sci., 17(2): 346-350.

Kumaral, N.A., Kovanci, B and Akbudak, B. 2007. Life tables of the olive leaf moth, Palpita unionalis Hubner on different host plants. J. Biol. Environ. Sci., 1(3): 105-110.

Naik, V.C.B., Rao, A.P., Krishnayya, P.V. and Rao, V.S. 2008. Seasonal incidence and Management of Leucinodes orbonalis. Annals of Plant Protection Sci., 16: 329-332

Pramanik, P., Mondal, P. and Chatterjee, M. 2012. Studies on biology of brinjal shoot and fruit borer, Leucinodes orbonalis (Guenee) under laboratory conditions. Int. J. Bio-res. Stress Manage, 3(3): 336-340.

Raju, S.V.S., Bar, U.K., Uma Shankar and Kumar, S. 2007. Resistant Pest Management Newslett., 16: 14-16.

Singh, R.R.K and Singh, T.K. 2009. Life table studies on brinjal shoot and fruit borer Leucinodes orbonalis. Annals of Plant Protection Sci., 17(2): 341-345.

Southwood, T.R.E. 1978. Ecological Methods with particular reference to study of insect populations. The English Language Book Society. Chapman and Hall, London. 524.

\section{How to cite this article:}

Ramesh, S., and Narendra Reddy, C. 2017. Studies on Life Fecundity Tables of L. orbonalis Guenee on Brinjal. Int.J.Curr.Microbiol.App.Sci. 6(2): 1620-1628. doi: http://dx.doi.org/10.20546/ijcmas.2017.602.180 